\title{
Precision glass molding: Toward an optimal fabrication of optical lenses
}

(C) The Author(s) 2017. This article is published with open access at link.springer.com and journal.hep.com.cn

\begin{abstract}
It is costly and time consuming to use machining processes, such as grinding, polishing and lapping, to produce optical glass lenses with complex features. Precision glass molding (PGM) has thus been developed to realize an efficient manufacture of such optical components in a single step. However, PGM faces various technical challenges. For example, a PGM process must be carried out within the super-cooled region of optical glass above its glass transition temperature, in which the material has an unstable non-equilibrium structure. Within a narrow window of allowable temperature variation, the glass viscosity can change from $10^{5}$ to $10^{12} \mathrm{~Pa} \cdot \mathrm{s}$ due to the kinetic fragility of the super-cooled liquid. This makes a PGM process sensitive to its molding temperature. In addition, because of the structural relaxation in this temperature window, the atomic structure that governs the material properties is strongly dependent on time and thermal history. Such complexity often leads to residual stresses and shape distortion in a lens molded, causing unexpected changes in density and refractive index. This review will discuss some of the central issues in PGM processes and provide a method based on a manufacturing chain consideration from mold material selection, property and deformation characterization of optical glass to process optimization. The realization of such optimization is a necessary step for the Industry 4.0 of PGM.
\end{abstract}

Keywords precision glass molding, optical lens, constitutive modeling, optimization, manufacturing chain, Industry 4.0

Received August 30, 2016; accepted October 10, 2016

Liangchi ZHANG ( ( ), Weidong LIU

Laboratory for Precision and Nano Processing Technologies, School of Mechanical and Manufacturing Engineering, The University of New South Wales, Sydney NSW 2052, Australia

E-mail: Liangchi.zhang@unsw.edu.au

\section{Introduction}

Advanced glass lenses are important components to many modern technologies [1-5]. A lithography process in the semiconductor industry, for example, relies on the quality of its optical system [6-9]. Reducing the feature size of a microchip from 42 to $10 \mathrm{~nm}$ using the ultraviolet lithography technique requires that the key optical element of the lithography system needs a flatness of $2 \mathrm{~nm}$ across an area of $30 \mathrm{~cm}[10]$. An advanced laser system demands high-quality microlens arrays to enhance the laser intensity [11-14]. The development of space telescopes calls for ultra-precision, large-scale glass lens to explore the universe [15-18]. Electronic devices in the consumer industry are also examples of application of precision lenses, such as the aspherical lenses for smart mobile phones and large-scale liquid crystal display panels $[1,19$ 21].

Traditional methods of fabricating glass lenses are grinding, polishing and lapping [22-25], dating back to the 1500 s when microscopes $[26,27]$ and telescopes [28$30]$ were invented. However, lens polishing skills were among talented craftsmen [26,28], developed from their life-long experience. The invention and application of grinding and polishing machines in the 1800s largely improved the efficiency of lens production [26,28]; these machines at that stage could only produce spherical lenses with rough surfaces. To avoid spherical aberration, one had to use a set of spherical lenses in an optical device [1]. The recent advances in computer numerical control machining have overcome many of the difficulties in the production of precision glass lenses [31,32]. However, the processes of precision machining, including single-point diamond turning, grinding, polishing and lapping, is still very time consuming and expensive. An aspheric optical element can easily cost some thousands of dollars [33]. Moreover, single point diamond turning, which is flexible to make precise and complex micro/nano features on a lens surface, is not suitable for the most needed optical material, the $\mathrm{Si}$ based optical glass. This is because silicate optical glass 
can easily produce severe cleavages and microchipping on a diamond tool surface and therefore bring about tool wear [34-36].

The technique of precision glass molding (PGM) has been developed for the manufacture of aspherical and irregular glass optics [37-39]. This technique is based on the softening of glass in its super-cooled liquid region which is above the glass transition temperature $T_{\mathrm{g}}$ [40]. With this, once the surface of a mold cavity is made to have the required dimensions, geometries and features, in a single production step a precision glass lens can be thermally formed to copy the cavity geometries and features of the mold. Figure 1 is a comparison of the PGM with the traditional machining process. It is clear that the PGM can significantly reduce the production time and cost.

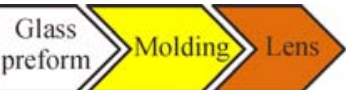

Precision molding process

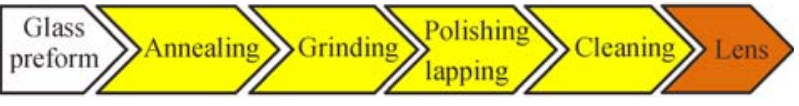

Machining process

Fig. 1 A comparison of traditional machining process with PGM

It has been found, however, that the quality of a molded lens depends on many factors in its PGM process, such as the mold material selection, the mold quality, the glass property change in PGM and the process control including temperature and pressure variations [41]. Any imperfection in each will influence the quality of a lens molded. A PGM process involves heating, soaking, molding, first cooling, demolding and final cooling, through which both the glass and mold experience complicated thermo-mechanical deformation. For example, in a very narrow temperature range the viscosity of glass undergoes a change of several orders of its magnitude, which brings about significant challenges for the production of high precision lenses by PGM [40]. As a result, the quality of the molded lenses is still not as good as those manufactured by precision machining processes, although the production cost of the former is only half of that of the latter [42]. It has therefore been a major research effort in the optics manufacturing field to try to greatly improve the PGM technology for making optics of the same or even higher quality compared with the products from the ultra-precision machining approach.

The brief discussion above shows that to produce precision lens by PGM, an optimal process based on a comprehensive consideration of the PGM manufacturing chain is necessary. Thus, after an introduction to the PGM in Section 2, this paper will focus on the investigations into the central problems individually in the manufacturing chain, as shown in Fig. 2, i.e., mold material selection (Section 3), property and deformation characterization of optical glass (Section 4), and process optimization (Section 5).

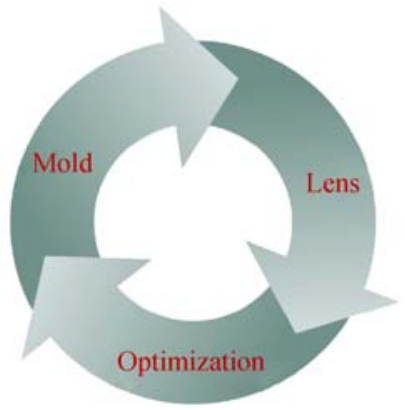

Fig. 2 Key factors in the manufacturing chain of a PGM process

\section{Precision glass molding}

PGM is a thermal forming process, which involves the heating of an optical glass preform to above its glass transition temperature $\left(T_{\mathrm{g}}\right)$, the compression forming of the preform in a mold cavity mechanically, and the cooling and demolding of the formed element. A PGM process needs to be carried out in a precisely controlled environment [41], including thermal and mechanical loading-unloading. This section will briefly introduce some commonly used moldable optical glasses, the typical procedure of PGM process and the achieved performance of molded lenses.

\subsection{Moldable optical glass and preforms}

Most optical glass materials have super-cooled liquid regions, in which the materials become soft and moldable $[33,41]$. In production, the efficiency and cost are important factors to be considered. In general, optical glass with a lower $T_{\mathrm{g}}$ has a higher moldability, with which the molding temperature is lower, the shape distortion due to cooling is smaller, the material property change in PGM is less, and the mold service life is longer. Table 1 [41] lists the definition of moldable glass supplied by a number of glass manufacturers. Figure 3 [33] summarizes the moldable glasses available with their key optical properties, index of refraction $n_{\mathrm{d}}$ and Abbe number $v_{\mathrm{d}}$.

Table 1 Moldable glass defined by manufacturers [41]

\begin{tabular}{lcc}
\hline Manufacturer & Prefix & Definition \\
\hline CDGM & $\mathrm{D}$ & $T_{\mathrm{g}}<618{ }^{\circ} \mathrm{C}$ \\
Hikari & $\mathrm{Q}$ & $T_{\mathrm{g}}<607{ }^{\circ} \mathrm{C}$ \\
Hoya & $\mathrm{M}$ & $T_{\mathrm{g}}<560{ }^{\circ} \mathrm{C}$ \\
Ohara & $\mathrm{L}$ & $T_{\mathrm{g}}<608{ }^{\circ} \mathrm{C}$ \\
Schott & $\mathrm{P}$ & $T_{\mathrm{g}}<550{ }^{\circ} \mathrm{C}$ \\
Sumita & $\mathrm{K}$ & $T_{\mathrm{g}}<530{ }^{\circ} \mathrm{C}$ \\
\hline
\end{tabular}


After the selection of a glass material, a proper glass preform for a specific optical lens/component needs to be determined, of which the quality will have a direct influence on that of the product. There are many different preforms in terms of shapes and sizes, such as a ballpreform. The advantages of a ball-preform are (1) that its spherical shape can be easily deformed in PGM into many commonly used lens geometries; and (2) that the ballpreform manufacture is already mature - High quality and low cost. Most suppliers can provide ball preforms of diameters from 1 to $8 \mathrm{~mm}$ [41]. However, very small or large preforms are still difficult to manufacture [41].

Flat preforms of optical glass are also commonly used in PGM. Compared to the ball-preform, a flat preform can be polished to a very high surface finish, and thus can be used for molding micro/nano micro-lens arrays, V-groove arrays, and other thin components [41]. Flat preforms are also suitable for molding diverging lenses because a flat surface can be deformed easily to either a concave or a convex shape [41].

To mold an optical component with a complex geometry or of a large dimension, a near-net shape preform is often required to minimize the geometrical change in PGM, although producing a near-net shape preform is expensive.

\subsection{Typical PGM procedure}

The proper glass preform now allows to have the PGM to happen on a molding machine. A PGM is a hightemperature compression forming process in a controlled environment [41], which includes heating, soaking, molding, cooling, demolding and final cooling, as shown in Figs. 4 and 5. The chamber of the PGM machine is evacuated with an inert gas, such as nitrogen, before heating the preform and mold up to the required molding temperature above the glass $T_{\mathrm{g}}$. This will make the glass viscosity be in the range of $10^{7}$ to $10^{8} \mathrm{~Pa} \cdot \mathrm{s}$ [40]. The process is then conducted by applying either a constant compression force or a pressing velocity within a period of time selected. At the end of the molding, the lens is first

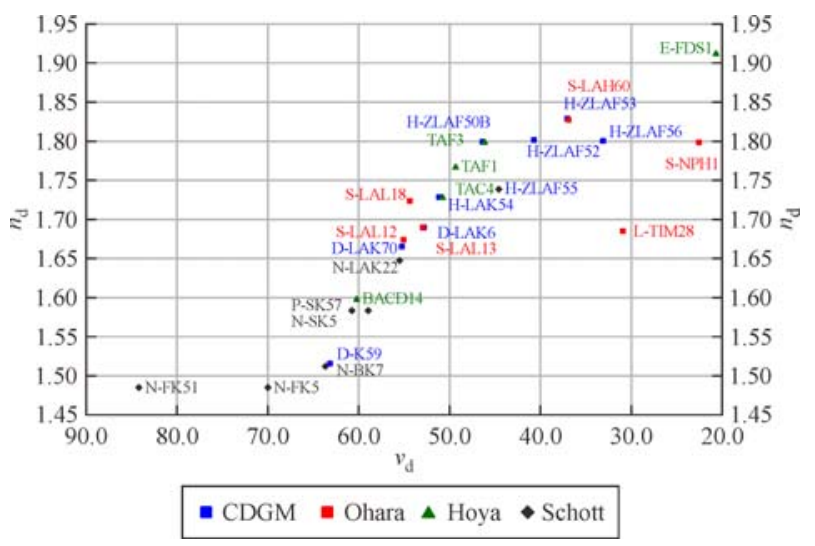

Fig. 3 Moldable optical glass available [33]

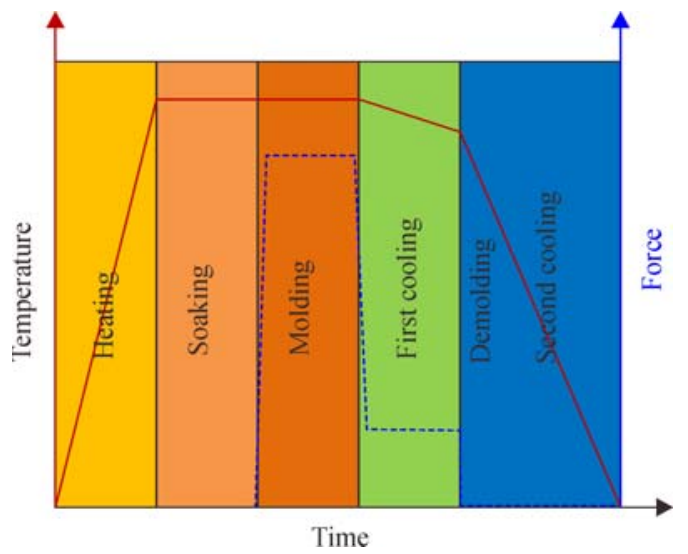

Fig. 4 A typical processing cycle of PGM

cooled down with a small rate, during which the compressive force remains until the glass temperature has dropped to a specific temperature corresponding to the strain point of glass $\left(\eta=10^{13.5} \mathrm{~Pa} \cdot \mathrm{s}\right)$. The demolding process can then take place associated with a higher cooling rate for a higher production efficiency $[40,41]$.

\subsection{Performance of molded optical lenses}

Most of the standard lenses can be manufactured by PGM with a reasonable quality, including biconvex, planoconvex, plano-concave or meniscus. It is cost-effective if a lens can be molded by using a preform commercially available. The manufacture of a mold cavity with very small or steep features is difficult. Large lenses also add difficulties and production cost due to the increased difficulties in quality control. The maximum size of molded lens was in the order of $100 \mathrm{~mm}$ in diameter [42]. Molding diffractive lenses is still challenging because grinding complicated diffractive features in the cavity surface of a carbide or ceramic mold is very difficult [43].

Table 2 [41] shows some typical tolerances of the lens by PGM. It should be noted that the tolerances depend on many factors and those in the table are not exhaustive. For example, the size and shape of a lens can have a significant impact on the tolerance actually achievable.

In PGM, mold deterioration and shape and optical property variations of molded lenses are major problems $[33,40,44-47]$. The manufacture of a quality optical mold is the costliest part in the PGM production chain. For example, a general PGM mold that costs about 4000 USD can fail within 1000 of molding cycles [48]. Thus, the selection of a suitable mold material is central to both the production quality and cost. The geometry accuracy of a lens molded is related directly to the complicated deformation of the glass material during the molding and cooling in a PGM, which cannot be clarified by a trial-anderror approach. Moreover, molding introduces residual stresses in a lens molded, which in turn alters the refractive 


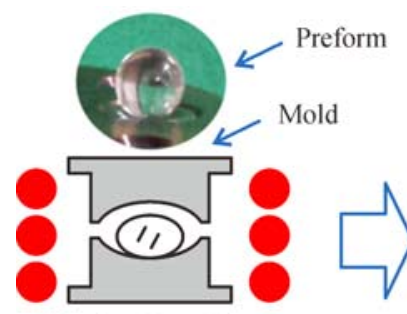

Heating \& soaking
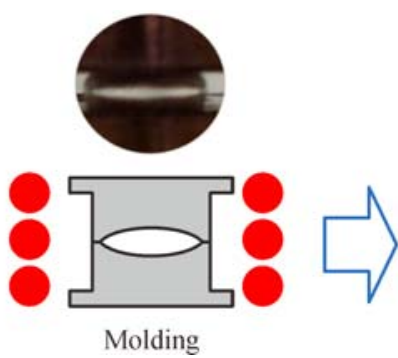

Fig. 5 A typical PGM process

Table 2 Typical tolerances for a precision glass molded lens [41]

\begin{tabular}{lccccccc}
\hline & $\begin{array}{c}\text { Center thickness } \\
/ \mathrm{mm}\end{array}$ & $\begin{array}{c}\text { Diameter } \\
/ \mathrm{mm}\end{array}$ & $\begin{array}{c}\text { Decentration } \\
/ \mathrm{mm}\end{array}$ & $\begin{array}{c}\text { Wedge } \\
/\left({ }^{\prime}\right)\end{array}$ & $\begin{array}{c}\text { Power/irregularity } \\
/ \text { fringes }\end{array}$ & $\begin{array}{c}\text { Surface } \\
\text { roughness/nm }\end{array}$ & $\begin{array}{c}\text { Surface quality } \\
\left(\mathrm{scratch} \cdot \mathrm{dig}^{-1}\right)\end{array}$ \\
\hline Commercial & \pm 0.050 & \pm 0.025 & \pm 0.020 & \pm 10 & $5 / 2$ & 20 & $60-40$ \\
Precision & \pm 0.025 & \pm 0.015 & \pm 0.010 & \pm 3 & $3 / 1$ & 10 & $40-20$ \\
\hline
\end{tabular}

index and Abbe number of optical glass $[41,45,46,49-51]$. Hence, a sophisticated study on the complicated mechanical behavior of optical glass in PGM is imperative. These problems will be addressed individually in the following sections.

\section{Mold material selection}

A mold replicates the optical prescription of a lens thermally formed and thus directly affects the optical quality of the product. The basic requirements for a mold of PGM are: (1) Excellent mechanical properties and wear resistance, (2) small coefficient of thermal expansion, (3) outstanding thermal stability, and (4) good machinability.

\subsection{Mold materials}

The first consideration in selecting a mold material is the $T_{\mathrm{g}}$ of the glass to be molded. As shown in Table 3 [41], it can be an ultra-low- $T_{\mathrm{g}}$ PGM, a low- $T_{\mathrm{g}}$ PGM or a high- $T_{\mathrm{g}}$ PGM. Electroless nickel-phosphor is a commonly used mold material for an ultra-low- $T_{\mathrm{g}}$ PGM, because this material is hard, and has high wear and corrosion resistance at a moderate temperature [52-54]. It has also a high machinability for single point turning [55,56]. However, this material can be crystallized and annealed at a temperature above $400{ }^{\circ} \mathrm{C}$; after which its properties are deteriorated [57]. Thus, electroless nickel-phosphor is suitable only to ultra-low- $T_{\mathrm{g}}$ PGM processes.

Compared with the mold material property requirement by an ultra-low- $T_{\mathrm{g}}$ PGM, the low- $T_{\mathrm{g}}$ PGM calls for a much harder substrate. Hence, tungsten carbide (WC) [58] and ceramics such as silicon carbide $(\mathrm{SiC})[59,60]$ are often used. However, because of the hardness and brittleness of these materials, their machinability by traditional methods is poor. In general, using a pre-shaped green mold can reduce significant workload in achieving the optical surface finish by precision grinding [41]. Depending on the requirements for molding specific lenses, polishing may need to be used to remove any residual grinding defects and minimize surface roughness.

Generally, optical glass with a high $T_{\mathrm{g}}$ of greater than $620{ }^{\circ} \mathrm{C}$ is not suitable for PGM because of the material's low moldability but high cost. Fortunately, lower $T_{\mathrm{g}}$ glass can be used in most cases [41] apart from some specific applications which require the use of high $T_{\mathrm{g}}$ glass (e.g., quartz glass with $T_{\mathrm{g}}=1200^{\circ} \mathrm{C}$ ). Some people suggested that amorphous glass/carbon molds can work at a high temperature up to $1500{ }^{\circ} \mathrm{C}$ [61]. However, a recent investigation found that oxidation-induced property deterioration and thermal mismatch problems of this types of materials will cause instability of the molds [62].

At a high temperature, a mold can wear quickly in its direct interactions with glass workpieces during molding.

Table 3 Selection of mold materials for different PGM processes [41]

\begin{tabular}{lccc}
\hline Process & Ultra-low $T_{\mathrm{g}}$ & Low $T_{\mathrm{g}}$ & High $T_{\mathrm{g}}$ \\
\hline$T_{\mathrm{g}}$ of glass & $<400{ }^{\circ} \mathrm{C}$ & $400{ }^{\circ} \mathrm{C}<T_{\mathrm{g}}<620{ }^{\circ} \mathrm{C}$ & $T_{\mathrm{g}}>620^{\circ} \mathrm{C}$ \\
Molds & Electroless nickel-phosphor & Carbides or ceramics & Carbides or ceramics \\
Manufacturing process & Single point diamond turning & Micro-grinding & Micro-grinding \\
Cost & Low & High & Very high \\
Tooling life & Low & Medium & Very low \\
\hline
\end{tabular}


Thus, coating is often used for extending mold life and thereby leading to the cost reduction of the molded optical products. There are mainly three types of coatings available in the market, namely, ceramic coating (TiAlN, $\mathrm{CrN}$, TiBCN or TiBC) [63], noble metal coating ( $\mathrm{Pt} / \mathrm{Ir}$ $[64,65]$ and $\operatorname{Re} / \operatorname{Ir}[66,67]$ ), and carbon coating (diamondlike coating, amorphous carbon coating) [68]. Ceramic coatings have been widely used in making machining tools, and therefore are straightforward to apply to PGM molds. However, most ceramic coatings are prone to adhesion with glass [64]. Noble metal coatings, especially the Pt/Ir alloy coating, can avoid such adhesion [64,65]. Nevertheless, it has been found that the $\mathrm{Pt} / \mathrm{Ir}$ layer is not stable [66,67], and that the substrate material can diffuse into the coating layer and reduce its quality. However, the noble metal coating of $\mathrm{Re} / \mathrm{Ir}$ demonstrates very stable properties [66] and low wetting angle among various coating materials [67]. Diamonds-like coatings require a vacuum environment to avoid oxidation at high temperature. Its performance still needs further studies $[68,69]$.

\subsection{Selection of mold materials}

The wear and fatigue of a mold are due to the cyclic mechanical stressing, and harsh heating and cooling in PGM production. An appropriate assessment or test is thus important when selecting proper mold/coating materials. The cyclic mechanical loading-unloading on a mold surface is through the mold-workpiece mechanical interactions (pressure and friction), which can result in the deformation, surface wear and fatigue failure of the mold. The repeated heating-cooling cycles, in thousands normally, not only bring about significant thermal stress variations in the mold, but also promote chemical reaction (e.g., diffusion and corrosion [48]) and adhesion between the mold and workpiece. The chemical reactions are mainly adhesion of glass on the coating, processes in the coating, and corrosive attack at the coating surface. These, in turn, can largely shorten the mold life.

In addition to the wear and fatigue considerations, the coefficient of thermal expansion (CTE) of the mold material, including that of the coating, must also be taken into account carefully. Ideally, the whole molding system composed of mold, coating and optical glass has the same CTE so that the glass-mold friction can be minimized and the accuracy of the molded optical lens can be maximized. This of course is impossible to achieve in practice, but aim to minimize the mismatch of the CTEs.

Some studies have been carried out to understand the effects of the above on the service life of PGM molds. These include the investigations on the sticking behavior of mold materials/coatings with hot glass preforms by the frequent contact method [70], the performance of different coatings in PGM [66,71], and the anti-sticking ability of $\mathrm{Pt} / \mathrm{Ir}$ and TiAlN coatings on tungsten carbide and silicon wafer substrates [65]. It was understood that compression hold time, cooling time and peak force can significantly affect the sticking.

However, most of the above works were conducted at a low temperature in a non-isothermal environment and as such the results are not directly applicable to a real PGM process. Recently, a quick testing facility [72,73] was proposed to assess the service life of mold coatings for PGM. It was noticed that in PGM a long period of time in the heating-cooling process is without mechanical stresses or chemical influence. From the pure mechanical wear and fatigue point of view, therefore, a cheap and simple testing facility, involving mechanical loading and unloading strokes only, may be used to bypass the time-consuming stages of heating and cooling. The performance of three standard coatings (TiAlN, CrAlN, and Pt/Ir) on flat WC pins was studied by using this type of testing, for the molding of B270 glass. Figure 6 [73] presents the images of the mold (pins) and glass imprints after 20 pressing steps, which shows clearly that the WC pins with Nitrogen coatings were severely worn. Edge damages and partial imprints took place on the corresponding glass specimen surfaces. However, the WC pin with the Pt/Ir coating remained undamaged.

\section{Property and deformation of optical glass}

With a proper mold selected, the second critical part in the manufacturing chain of optical lenses, as emphasized in Fig. 2, is to achieve an accurate understanding of the variation mechanisms of property and deformation behavior of optical glass in a PGM process. Otherwise, many critical issues which influence greatly the residual stresses, geometry distortion and optical properties of a molded lens cannot be controlled [33,40,44-47]. Many studies and production process designs have been trial-and-error, highly dependent on the practical experience and skills. For example, it usually needs 3 to 4 months of laborintensive refining process to reach a satisfactory mold geometry to compensate the shape deviation of a molded optical lens [74], at the cost of about 4000 USD [74].

It has been recognized that computer simulation can minimize the trial-and-error design process $[40,75,76]$. To obtain sophisticated solutions and useful guidelines for process optimization, the finite element (FE) method has been widely used to reveal the mechanism of geometry deviation and residual stresses [77,78]. This involves an accurate constitutive description of optical glass, the instantaneous property change of optical glass during the heating-cooling cycle in PGM, and lens distortion characterization. These will be discussed in the following sections.

\subsection{Constitutive modeling of optical glass}

To make a reliable numerical simulation, it is essential to 

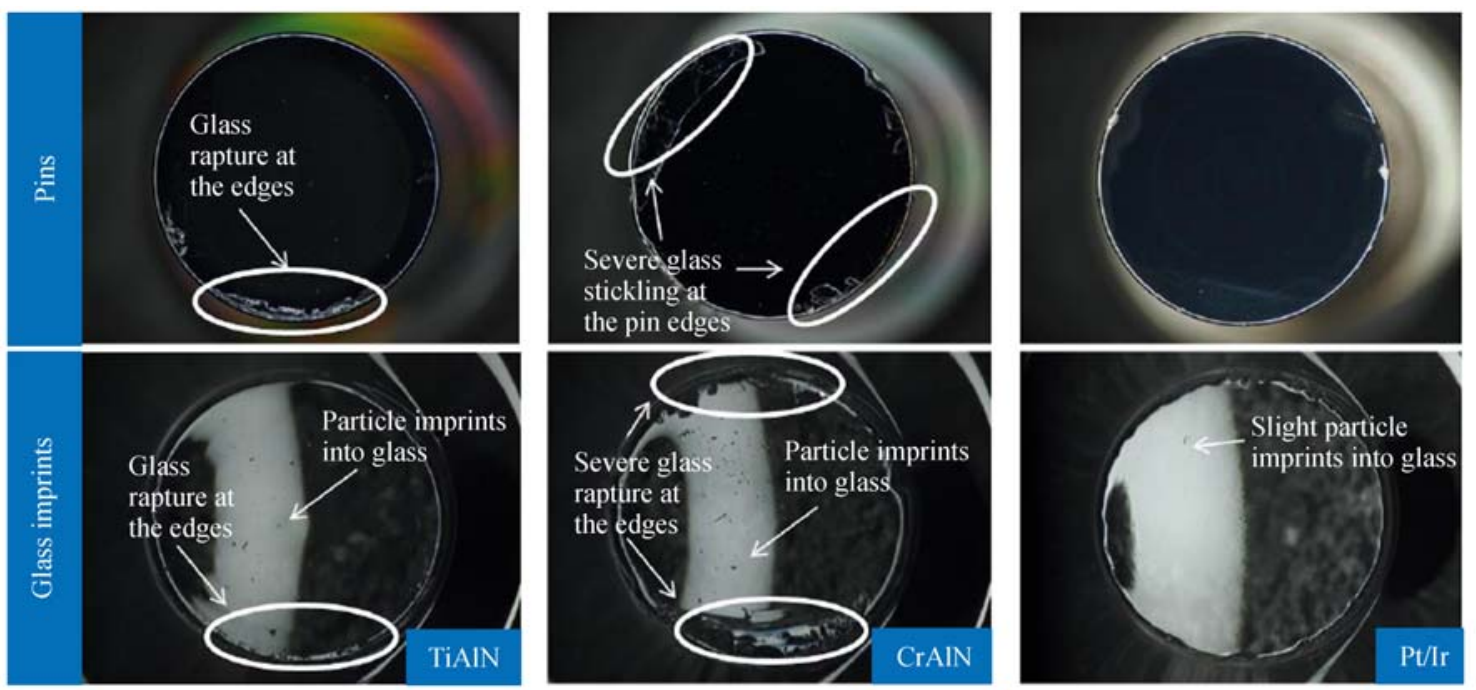

Fig. 6 Performance comparison of TiAlN, CrAlN and Pt/Ir coatings after 20 pressing steps [73]

use reliable constitutive models that can accurately describe the behavior of optical glass throughout a PGM process. However, to establish such models is challenging because the behavior of optical glass during the thermalmechanical deformation in PGM is strongly nonlinear and complicated. In general, a complete constitutive model of glass suitable for PGM should be able to the following relationships of mechanics quantities: (1) The thermoviscoelastic relationship of stress, strain, strain rate and temperature, and (2) the nonlinear temperature dependence of the material properties [40].

A significant effort has been placed to develop constitutive models for describing the thermomechanical behavior of optical glass in PGM. Some used measured thermo-viscoelastic properties of the materials (BK-7 and TaF-3 [75]), obtained the viscoelastic property of glass by using the relaxation data from a cylinder compression test with the assumption of incompressibility [76], or treated glass as an elasto-viscoplastic material to account for the strain rate effect [79]. In most of these works the temperature-dependent rheology was modeled by the classical phenomenological Vogel-Fulcher-Tammann equation [37] or the thermos-rheological simple assumption $[75,77]$, in which the parameters need to be obtained by curve fittings to a series of viscosity tests. Recently, a method was proposed for identifying the shear relaxation modulus and the structural relaxation function via measuring the time variation of the glass plate thickness [80]. The CTE variation was often modeled by the ToolNarayanaswamy-Moynihan (TNM) model [77,78], the parameterization of which needs structure relaxation tests and thermal expansion tests. It is clearly complicated to establish a constitutive model using these methods.

A modulus-based constitutive model, as summarized in Table 4, was recently developed for analyzing PGM processes numerically [40]. The core of this approach is that all the temperature-dependent material properties are determined by the relationship between the elastic moduli and microstructure of a material. In this model [40], the strain tensor and stress tensor are divided into volumetric and deviatoric parts. The relationship between deviatoric stress and strain is described by a standard linear solid (SLS) model [81]. Because of the strong resistance to volumetric changes, the bulk viscosity of optical glass (PBK7) can be considered to be infinite, and thus a simple thermal elastic relationship is enough. Temperaturedependent Young's modulus, shear modulus, and bulk modulus can be measured straightforwardly by an impulse

Table 4 Modulus-based constitutive model for optical glass [40]

\begin{tabular}{lc}
\hline Relationship & Equation \\
\hline Stress and strain & $\varepsilon_{i j}=e_{i j}+\operatorname{tr}(\varepsilon) \delta_{i j} / 3, \sigma_{i j}=S_{i j}+\operatorname{tr}(\sigma) \delta_{i j} / 3$ \\
Volumetric relationship & $\operatorname{tr}(\varepsilon) / 3-\alpha \Delta T=\operatorname{tr}(\sigma) / 9 K$ \\
Deviatoric relationship & $\left(1+\frac{G_{r}}{G}\right) \dot{e}_{i j}+\frac{G_{r}}{\eta_{\mathrm{s}}} e_{i j}=\frac{S_{i j}}{2 G}+\frac{S_{i j}}{2 \eta_{\mathrm{s}}}$ \\
Viscosity variation & $\eta_{\mathrm{s}}=\eta_{0} \exp \left(V_{\mathrm{c}} G_{\infty}(T) / k_{\mathrm{B}} T\right)$ \\
Thermal expansion & $\alpha=\alpha_{\mathrm{G}}+\left(\alpha_{\mathrm{L}}-\alpha_{G}\right) \delta T_{\mathrm{f}} / \delta T$ \\
Structure relaxation description & $T_{\mathrm{f}}=T-\int_{\xi\left(T_{0}\right)}^{\xi(T)} M_{\mathrm{p}}\left(\xi-\xi^{\prime}\right) \frac{\mathrm{d} T}{\mathrm{~d} \xi^{\prime}} \mathrm{d} \xi^{\prime}$ \\
& $\xi=\int_{0}^{t} 1 / \tau_{\mathrm{p}} \mathrm{d} t^{\prime}$ \\
& $M_{\mathrm{p}}(\xi)=\exp \left[-\left(\xi / \tau_{\mathrm{pr}}\right)^{\beta}\right]$ \\
& $\tau_{\mathrm{p}}=\tau_{0} \exp \left[x \Delta H / R T+(1-x) \Delta H / R T_{\mathrm{f}}\right]$
\end{tabular}

$\varepsilon_{i j}$-Strain tensor; $\sigma_{i j}-$ Stress tensor; $e_{i j}$-Deviatoric strain; $S_{i j}$-Deviatoric stress; $\operatorname{tr}(\varepsilon)$ - The trace of the strain tensor; $\operatorname{tr}(\sigma)$ - The trace of the stress tensor; $\delta_{i j}$ - Kronecker delta; $K$-Bulk modulus; $\alpha$-The coefficient of thermal expansion; $T$-Temperature; $G_{r}$-The modulus in the elastic branch of the SLS model; $G$-The shear modulus in the Maxwell branch of the SLS model; $\eta_{\mathrm{s}}-$ Shear viscosity; $\eta_{0}$-Reference viscosity; $k_{\mathrm{B}}$ - Boltzmann constant; $V_{\mathrm{c}}-$ Characteristic temperature-independent microscopic volume; $G_{\infty}(T)$-Instantaneous shear modulus; $\alpha_{\mathrm{G}}-$ The reference CTE at low temperature glassy state; $\alpha_{\mathrm{L}}-$ The reference CTE at high temperature liquid state; $T_{\mathrm{f}}$-Effective temperature; $T_{0}$-The reference temperature; $M_{\mathrm{p}}(\xi)-$ The structural relaxation function; $\xi$-Reduced time; $\tau_{\mathrm{p}}$-Structural relaxation time; $\Delta H$-The active energy; $R$-The ideal gas constant; $\tau_{0}, x, \beta$-Constants 
excitation method [82]. Based on the shoving model [83], the temperature-dependent viscosity of optical glass can then be directly linked to its shear modulus, and the CTE of glass can be predicted through modulus based on a phenomenological TNM model [77,78], in which the parameters needed in TNM model can be determined by the modulus changes along with the temperature in the impulse excitation method. The above constitutive model with the measured/derived parameters has been verified and programmed into ABAQUS as a user material (UMAT) [40].

\subsection{Mechanisms of lens distortion}

Lens accuracy, including lens geometrical accuracy and quality of its surface finish, is critical. Ultra-precision grinding, polishing and lapping can achieve high lens accuracy step by step at a high cost. The surface and shape accuracy of a lens by PGM, however, are formed in a single thermal forming step at high temperature [40]. In general, the quality of a molded lens, both surface and shape accuracy, depends largely on that of the mold surface and the lens distortion during annealing, cooling and demolding. It was reported that the shape derivation of a molded lens can be as high as $20 \mu \mathrm{m}$, about 20 times higher than the deviation allowed according to the optical design specifications [74]. Thus, in designing a mold, the cavity cannot be simply the dimensions of the required geometry, but must include a compensation taking into account the distortion of the lens in PGM. Such compensation at the initial model design can be realized with the aid of numerical simulation using a proper constitutive model.

For example, the formation mechanism of shape deviation of lenses in PGM was investigated in detail by using the modulus-based constitutive model [40]. Figure 7(a) shows the evolution of shape variation of a lens during a typical PGM process. In the pressing (molding) stage, the glass ball (preform) was compressed to comply with the mold cavity. The subsequent demolding did not lead to a significant shape deviation. However, in the cooling stage, a large shape deviation occurred near the center of the lens, as shown in the figure insert. When the internal temperature of the lens reduces to below the material's $T_{\mathrm{g}}$, no further deviation occurs. The deviation details with respect to the mold in the radial direction are presented in Fig. 7(b). The large deviations near the center and the edge of the lens are due to the cooling-induced shrinkage and edge effect, respectively [40]. For a precision lens, the allowed center thickness change is about $25 \mu \mathrm{m}$ [41], and the maximum deviation of overall surface shape should be within several micrometers or smaller [77,78]. Thus, the above numerical analysis [40] has demonstrated that mold compensation is essential; otherwise the lenses by PGM are not usable.

The numerical analysis [40] can also identify the geometry effect and key processing parameters that

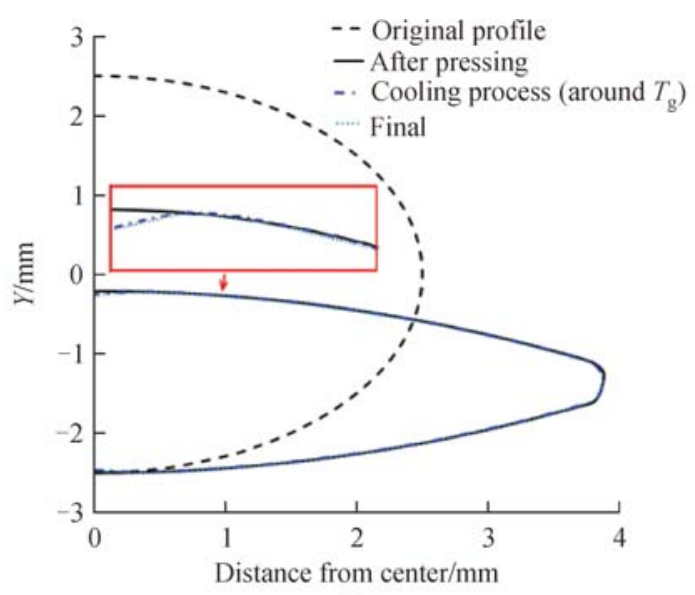

(a)

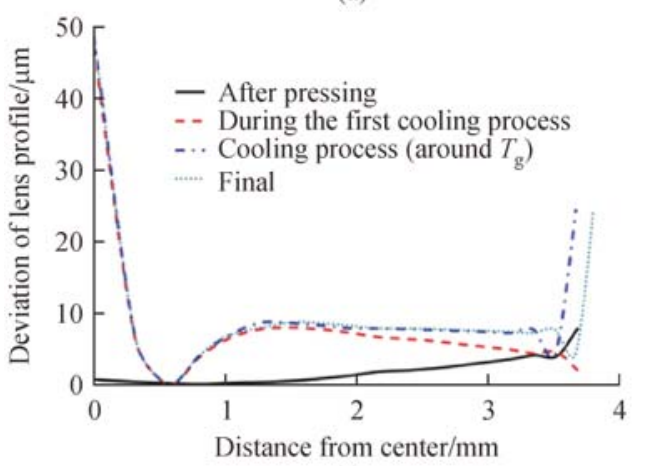

(b)

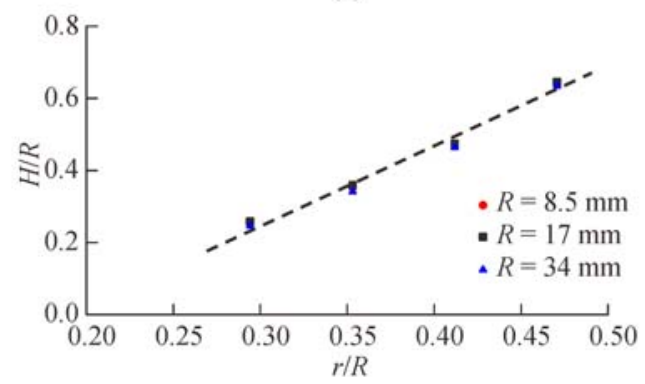

(c)

Fig. 7 (a) The evolution of a lens shape in PGM; (b) the deviation with respect to the mold cavity geometry; (c) the relationship between $H / R$ and $r / R$ [40]

influence the final shape. As shown in Fig. 7(c), the relationship between $H / R$ and $r / R$ is almost linear, in which $H$ is the final thickness of the molded lens, $R$ is the curvature radius of the mold, and $r$ is the radius of the glass ball-preform. This dimensionless result shows the geometry similarity of the glass molding process, indicating that if one gets the final shape of a lens at a certain dimension, lenses of the similar geometry of other dimensions can be predicted by this linear relationship if their forming conditions are the same. It should be noted, however, that this linear relationship is the result of a macroscopic analysis, and that nonlinear effects may arise in micro-lens.

It has also been reported [77,78], based on a parametric study on the formation mechanism of shape deviation, that 
the structural relaxation of glass is the primary reason for lens distortion in PGM [78]. The activation energy constant and relaxation time constant in the TNM model are key parameters of structural relaxation that affect the lens shape change [78,82]. Hence, glasses with different values of these parameters must be compensated differently. It is thus essential to have the structural relaxation parameters well defined to predict the deviation within tolerance. A novel method [82] has been developed recently to identify these parameters based on an impulse excitation technique.

Studies $[77,78]$ have suggested that the most critical stage to introduce lens distortion is at the beginning of demolding. The thermal expansion coefficients of the mold material and internal stresses of the lens play an important role in the shape deviation of lens. Other important factors include molding temperature, loading-unloading paths and cooling rates.

\subsection{Internal property change}

As mentioned in Section 2, some critical optical properties of glass can be changed after molding. This is because the cooling rate of glass material in PGM is different from that of glass preform. Most glass preforms have been well annealed by manufacturers. However, in PGM, fast cooling rates are often used to increase production efficiency and reduce cost. During the cooling stage of PGM, glass properties such as the CTE can change due to structural relaxation and lead to internal residual stresses [84-86]. It has been reported that residual stresses can severely alter the local density, and lead to inhomogeneous refractive index in an optical lens [84]. For instance, a residual stress of $3 \mathrm{MPa}$ in P-BK7 glass lens can bring about a variation of refractive index of $4 \times 10^{-4}$, and thus produce unwanted changes in the light path, intensity, and deterioration of image quality $[87,88]$. Therefore, it is important to understand the formation mechanism of residuals stresses in PGM process and its effect on optical properties.

Some studies showed that the duration of cooling from the molding temperature to $T_{\mathrm{g}}$ is important in minimizing residual stresses [75] and that the residual stresses in a molded lens can be controlled to a very small value if a proper cooling is applied [84]. Further, the evolving internal stresses within glass can be affected by changing the rheology behavior of glass at molding temperature, the friction at the glass/mold interface, and the time/temperature at which the demolding is applied [77,78].

A recently comprehensive investigation [40] revealed the formation mechanisms of residual stresses as well as some key parameters that affect the residual stresses. Figure 8 [40] shows some typical distributions of residual hydrostatic and von Mises stresses in a convex-convex lens by PGM. It can be seen that the inner part of the lens sustains tensile residual stresses, but its external surfaces are under high compressive stresses (Fig. 8(a)). The region between these two has low residual stresses, which is also

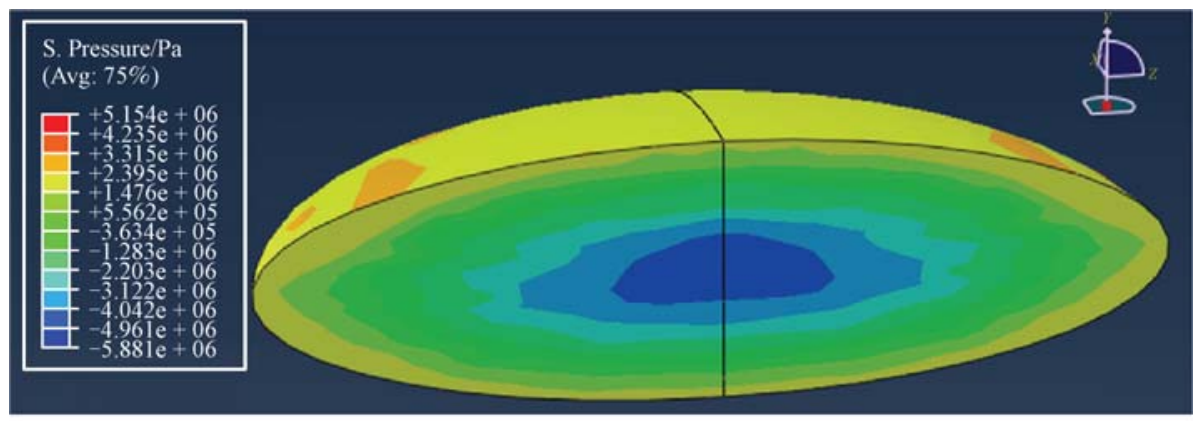

(a)

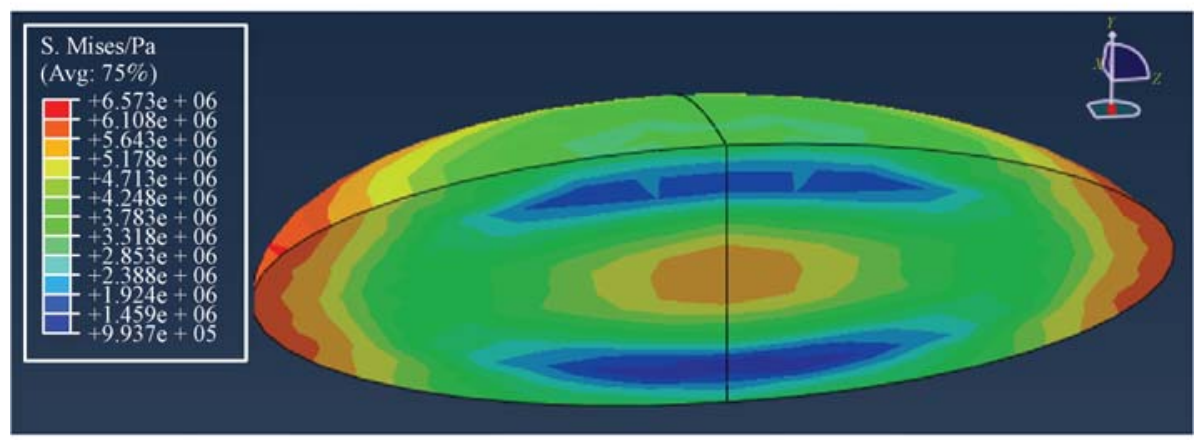

(b)

Fig. 8 The distributions of residual (a) hydrostatic stress, and (b) von Mises stress [40] 
true in the von Mises stress distribution (Fig. 8(b)) [40]. The two minima of the von Mises stresses locate closely to the top and bottom subsurfaces, symmetrically. It should be noted that lenses for different shapes can have very different distributions of residual stresses.

The formation mechanism of the residual stresses can be understood by monitoring the evolutions of the von Mises stresses in the lens. For convenience, let us investigate the stresses at the top, middle and bottom points of the lens [40] as shown in Fig. 9(a). It can be seen that the internal

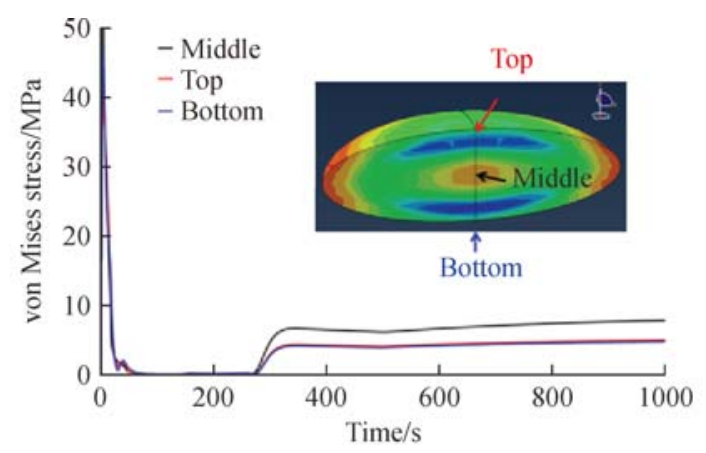

(a)

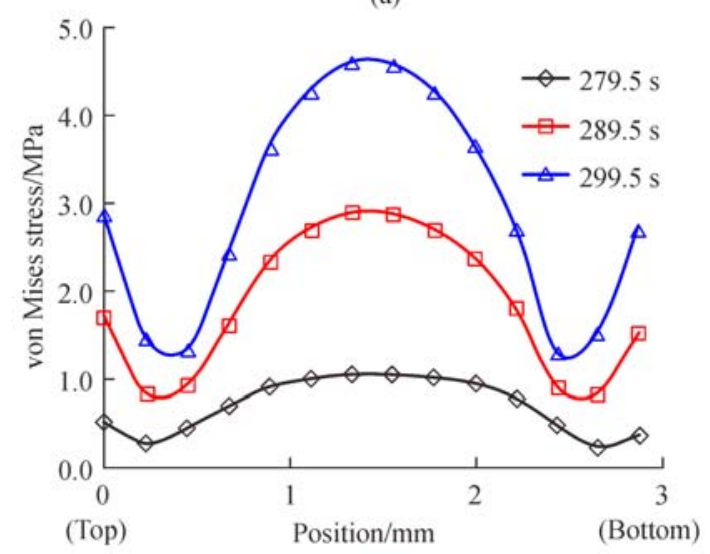

(b)

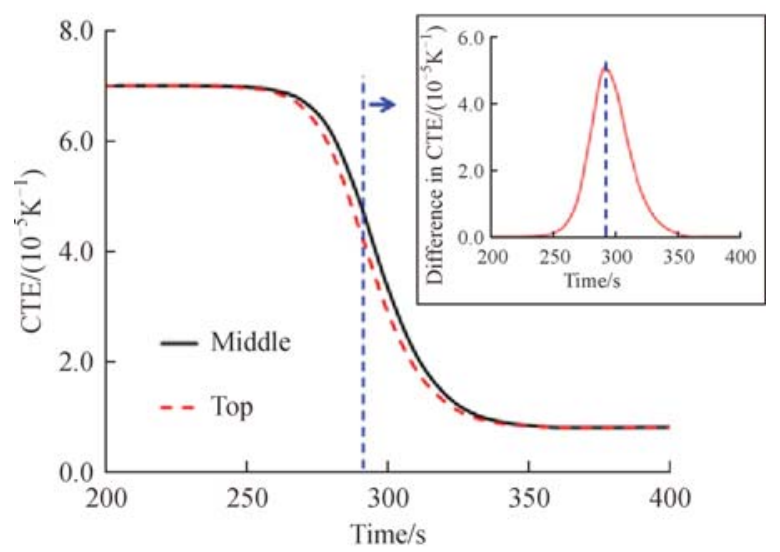

(c)

Fig. 9 (a) Variations of the von Mises stresses with time at different points in the lens; (b) the stress distributions along the central line through the lens thickness; (c) the variations of CTEs at different points with time [40] stresses before $270 \mathrm{~s}$ are very small except in the initial pressing stage. At around $270 \mathrm{~s}$ (in cooling stage), however, the internal stresses increase to a plateau till the end of the PGM process to form residual stresses. Figure 9(b) presents the internal stress distributions along the central line through the lens thickness at three different times around $270 \mathrm{~s}$. It is clear that both the magnitude and gradient of the internal stresses increase significantly in this region. The sharp internal stress increase is closely related to the heterogeneous evolution of CTE of the optical glass during PGM [40]. As shown in Fig. 9(c), in the time interval between 270 and $320 \mathrm{~s}$, the CTE decreases quickly when the lens temperature approaches $T_{\mathrm{g}}$ in the cooling stage. As the temperature distribution in the lens is inhomogeneous during glass molding, the changes of the CTE at different positions are asynchronous. The difference of CTEs reaches the maximum at 280 $\mathrm{s}$ as shown in the insert of Fig. 9(c), corresponding to the significant increase of the magnitude and gradient of the internal stresses.

Since residual stresses arise due to the sharp increase of internal stresses during cooling, it is reasonable to expect that residual stresses can be reduced by controlling the cooling rate. It has been found that the rate of the first cooling stage from the molding temperature to $T_{\mathrm{g}}$ is very important in minimizing the residual stress [75]. If this cooling stage can be of a sufficient duration, the second cooling stage from $T_{\mathrm{g}}$ to room temperature can be shorter [75]. A recent study [40] has explicitly shown the different effects of the two cooling stages on the formation of residual stresses (Fig. 10). Figure 10(a) demonstrates the evolutions of the von Mises stresses in a lens under three different cooling rates in the first cooling stage, but with a constant cooling rate of $1{ }^{\circ} \mathrm{C} / \mathrm{s}$ in the second cooling stage. It is clear that the internal stresses and residual stresses decrease if the first stage cooling rate is smaller (above $T_{\mathrm{g}}$ ). Figure 10(b) shows that varying the second stage cooling rate (below $T_{\mathrm{g}}$ ) has a negligible effect on the internal and residual stresses. Thus, to effectively minimize the residual stresses in a lens, a good strategy would be to use a small cooling rate in the first stage, and then a larger cooling rate in the second stage for the sake of production efficiency [40].

\section{Process optimization}

The quality of a lens manufactured by PGM is influenced by a series of factors such as the quality of the optical glass preform, quality of the mold (design, material and fabrication) and processing conditions/parameters of the molding process. Although the mechanisms of mold deterioration, lens shape distortion and residual stress have been studied, it is essential to make full use of the mechanisms explored in lens production to compensate the possible quality deviation of a lens from the beginning of a 


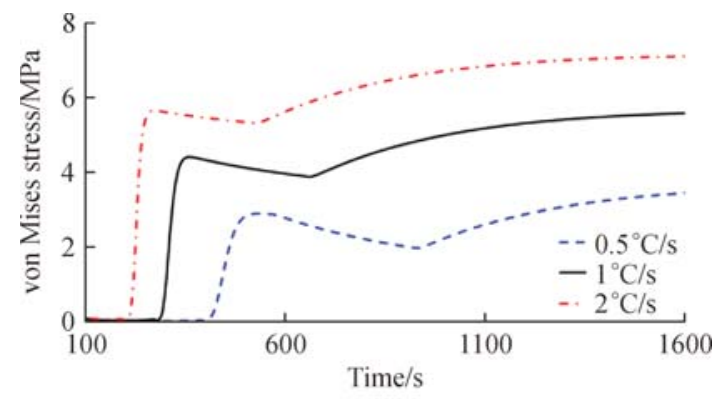

(a)

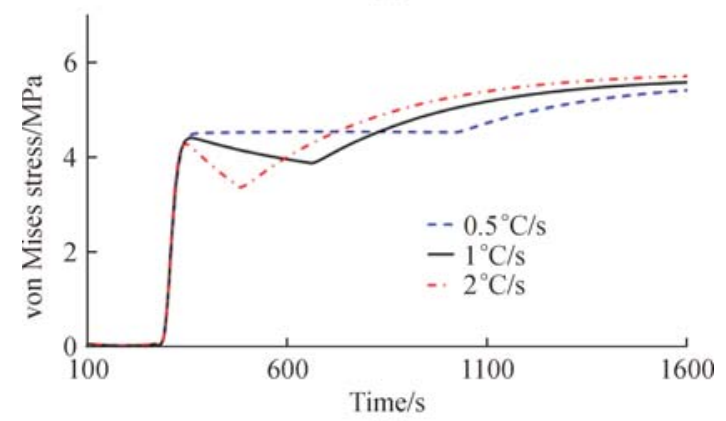

(b)

Fig. 10 The effect of cooling rate on the internal stresses with time: (a) Effect of cooling rates in the first cooling stage, and (b) effect of cooling rates in the second cooling stage [40]

PGM process design. As have been discussed in detail in the previous sections, the relationships between the product quality and control factors are complex and highly nonlinear. Any trial-and-error approaches of compensation cannot work effectively. A process optimization with the aid of a reliable numerical simulation is a cost-effective way to minimize the problems throughout the whole manufacturing chain of lens production. In the following, we will use a simple example to demonstrate the PGM optimization process, with a single optimization objective, from the point of view of the manufacturing chain consideration.

\subsection{Optimization strategy}

A process optimization usually consists of three parts: Determining realistic objective functions, selecting reliable optimization algorithms, and defining key criteria for optimization. As shown in Fig. 11, to optimize a PGM process of lens, the objective functions are not simple equations $[44,89,90]$. The criteria must be determined based on the objectives to be optimized. Briefly speaking, it gets the parameters to be optimized from the optimization algorithms based on the criteria established to come up with a set of results required for the design of the mold and PGM processing parameters. Generally, it is easier to optimize relevant factors for best values of a single objective, such as reducing the shape deviation by mold compensation or minimizing the residual stresses by

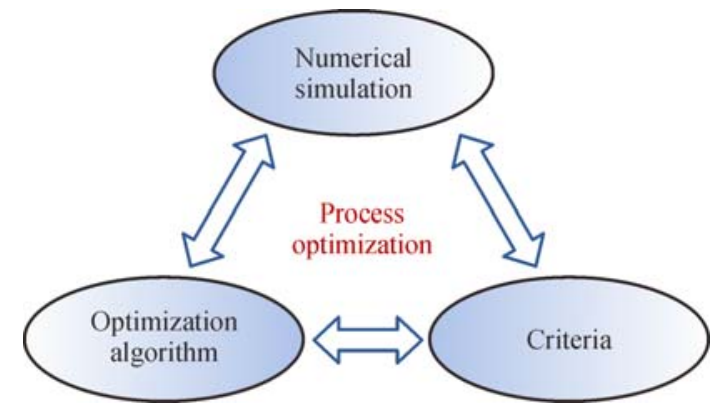

Fig. 11 A typical optimization process

selecting appropriate PGM parameters. These will be discussed individually below.

\subsubsection{Mold shape optimization}

According to the mechanism investigation highlighted previously, the lens shape distortion in PGM starts at the cooling stage due to the inevitable thermal shrinkage of optical glass. Thus, the mold geometry and dimension must be optimized to compensate such effects $[44,89,90]$. Different algorithms have been used for optimizing the mold shape, using, e.g., an iterative algorithm [91,92], a sequential quadratic programming method [90] or an iterative deviation method [44].

An authors' recent work (unpublished data) was completed by using a numerical optimization platform based on the simplex method and finite element simulation to give rise to the optimal design for producing a formulated aspherical lens surface defined by Eq. (1),

$$
Y(X)=\frac{X^{2}}{R\left(1+\sqrt{1-(1+k) \frac{X^{2}}{R^{2}}}\right)}+a X^{4},
$$

where $X$ is the distance from the lens axis, $Y$ is the $Y$ component of the distance from the vertex, $R$ is the radius of curvature, $k$ is conic constant, and $a$ is the correction coefficient of high order terms.

The advantages of using the formulated aspherical mold shape are: (i) The number of the optimization parameters is much less than that in the optimization of node positions in a finite element simulation, and (ii) the optimized parameters can be directly used by an ultra-precision machining system for making a mold. The profile-meansquare-deviation (PMSD), Eq. (2), is selected as the optimization objective.

$$
P M S D=\sqrt{\frac{\sum_{i=1}^{N}\left(y_{i}-\hat{y}_{i}\right)^{2}}{N}}<1 \mu \mathrm{m},
$$

where $N$ is the node number on the lens surface, $y_{i}-\hat{y}_{i}$ represents the shape derivation at the $i$ th node. A highquality optical lens requires the $P M S D<1 \mu \mathrm{m}$ [93], which 
is set as the optimization criterion in this optimization exercise.

Figure 12 shows changes of the PMSD with the optimization cycles on $R, k$ and $a$ simultaneously. The whole optimization process was completed in 22 cycles to satisfy the criterion, which gave rise to the optimized parameters of $R=11.785 \mathrm{~mm}, k=1.842593$ and $a=-$ 5.42653 with the optimized $P M S D=0.83205 \mu \mathrm{m}$ satisfying the criterion (ii).

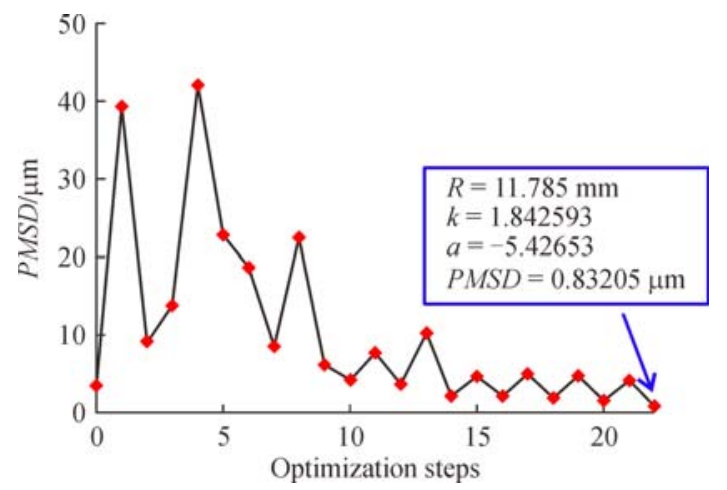

Fig. 12 Variation of $P M D S$ during the simultaneous optimization of $R, k$ and $a$

Figure 13(a) compares the shape deviations of the molded lens along its radial direction with and without the mold optimization. It can be seen that the large shape deviation near the edge has been effectively reduced by using the optimized mold. Figure 13(b) shows the

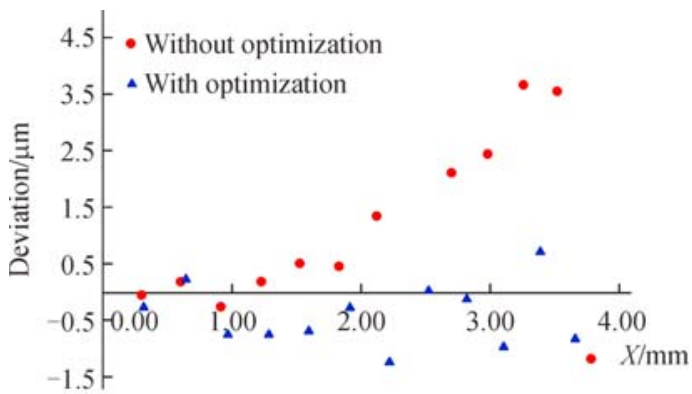

(a)

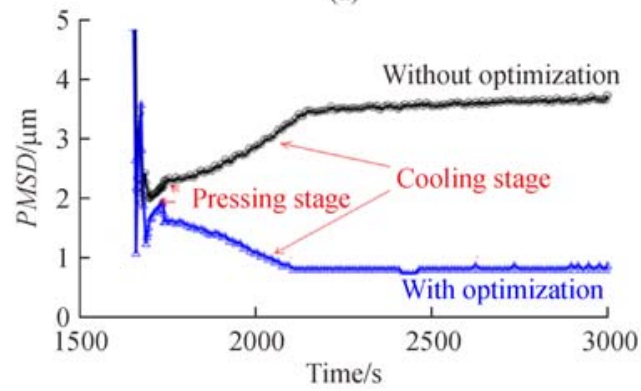

(b)

Fig. 13 (a) The comparison of the shape deviations of the molded lens along its radial direction with and without mold optimization; (b) the evolution of the PMSD during PGM evolution of the PMSD during the molding process with and without the mold shape optimization. It is clear that without the optimization, the shape deviation of the molded lens started from during the pressing stage and increased significantly during cooling. By using the optimized mold, however, the deviation can be effectively reduced during cooling. The mold compensation provides a much better lens shape.

\subsubsection{Residual stress optimization}

Compared to the mold geometry optimization, little has been done on that of the residual stresses. As revealed in Section 3, residual stresses in a lens form during lens cooling [40]. An optimization trial [94] has been on the whole cooling stage in PGM to make the residual stress below a prescribed threshold. Because the stress only relaxes in the temperature region from $T_{\mathrm{g}}-50$ to $T_{\mathrm{g}}+100$ ${ }^{\circ} \mathrm{C}$, the cooling curve in this region was defined by 7 key points to be optimized, as shown in Fig. 14 [94]. In this figure, $T_{\mathrm{a}}(t)$ is temperature, $t$ is time, and $t_{\mathrm{f}}$ is a critical cooling time. Figure 14 also showes the optimized cooling curves for different stress threshold.

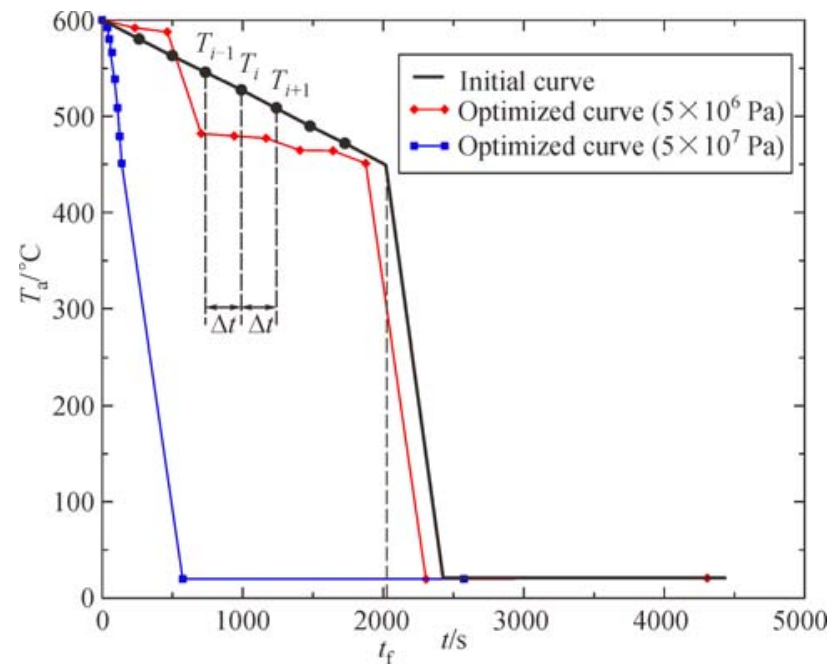

Fig. 14 Initial and optimized cooling curves [94]

However, by taking into account the fact that lens cooling can be divided into two stages, i.e., the first cooling stage influential to residual stresses and the second cooling negligible to residual stress generation, the residual stress optimization process can focus on the first cooling stage. Figure 15(a) presents the evolution of the parameters during optimization. The corresponding residual stress changes are given in Fig. 15(b), showing that the optimization enables the residual stress to decrease until reaching the criteria $(<2.5 \mathrm{MPa})$. An optimized cooling curve is then obtained for production use, which is difficult to obtain by any trial-and-error methods. 


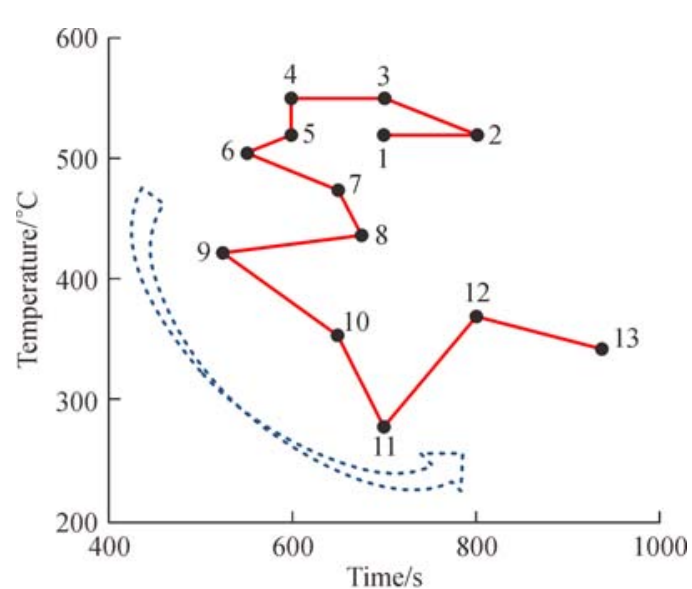

(a)

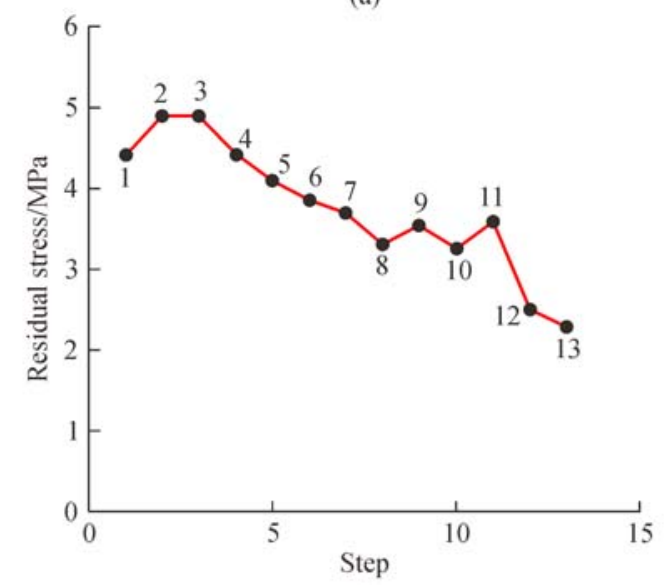

(b)

Fig. 15 (a) The optimization path, and (b) the corresponding residual stress

\subsection{Industry 4.0 for next generation of PGM}

Optimizing the whole manufacturing chain of PGM is much more challenging than the optimization based on a single objective introduced above. However, it is a necessary step to realize the Industry 4.0 of PGM. An effort has been placed to develop independent, web-based software for PGM, which can run on standard devices like laptops, smartphones and PCs [95] for all users to share, including process developers and quality control inspectors. In this way, one can collect all the digitalized data throughout the manufacturing chain of PGM, and further analyze the correlations between "input" preform, mold, processing parameters and "output" quality of the molded glass lenses. In this way, one can understand how a glass preform conforms to the cavity of a mold and how a molded lens cools down. The formation of shape deviation and residual stress can also be monitored in situ and can be linked to the product inspection. A real-time analysis of process data can then be realized to ensure that the required quality is achievable. The challenge of such PGM techniques is how to analyze the huge volumes of data to offer added value.

\section{Summary and perspectives}

This paper has reviewed the specifications, challenges and latest progress of PGM, a next-generation technique for producing high quality components of optical glass in a single production step. A brief summary and perspectives are given below.

1) PGM can significantly reduce the time and cost in producing glass optical components compared with traditional machining methods. The key to success is that PGM allows the replication of thousands of glass lenses using only a single mold.

2) Producing a quality component of optical glass requires a suitable preform, a well-designed and machined mold, and an optimized PGM process. Any defects in these preparatory elements will be transferred to the final products. The quality of molded lenses is still not comparable with those by ultra-precision machining. Further research is necessary.

3) Three major problems are limiting the quality the lenses by PGM: The shape deviation during demolding and cooling, the optical property changes due to structural relaxation and residual stresses, and the deterioration of molds and/or coatings. These problems are associated with many factors in a complex manner and cannot be solved by a trial-and-error method.

4) Multi-factor optimization is an effective way to make a PGM technique more superior to the ultra-precision machining approach. Although the one-objective optimization has been successfully applied to reduce the shape deviation and residual stresses in a molded lens, the optimization of the PGM manufacturing chain is essential to realize the Industry 4.0 of PGM.

\footnotetext{
Acknowledgements The work presented in this paper was financially supported by the Australian Research Council. This research was undertaken with the assistance of resources provided at the NCI National Facility systems at the Australian National University and Intersect Australia Ltd. through the National Computational Merit Allocation Scheme supported by the Australian Government.

Open Access This article is distributed under the terms of the Creative Commons Attribution 4.0 International License (http://creativecommons.org/ licenses/by/4.0/), which permits unrestricted use, distribution, and reproduction in any medium, provided you give appropriate credit to the original author(s) and the source, provide a link to the Creative Commons license, and indicate if changes were made.
}

\section{References}

1. Fischer R E, Tadic-Galeb B, Yoder P R. Optical System Design. New York: McGraw-Hill, 2008 
2. Erdenebat M U, Kwon K C, Dashdavaa E, et al. Advanced 360degree integral-floating display using a hidden point removal operator and a hexagonal lens array. Journal of the Optical Society of Korea, 2014, 18(6): 706-713

3. Li J, Hu S, Zhao L. Study of the influence of the shape of projection lens focal plane on the focus control of advanced lithography. Optik-International Journal for Light and Electron Optics, 2014, 125(22): 6775-6777

4. Tsai C M, Fang Y C, Hsiang C Z. A study of optical design and optimization applied to lens module of laser beam shaping of advanced modern optical device. Laser Beam Shaping XII, 2011, $81300 \mathrm{~W}$

5. Zhang Y, Milster T D, Kim J S, et al. Advanced lens design for bitwise volumetric optical data storage, Japanese Journal of Applied Physics, 2004, 43(7): 4929-4936

6. Harriott L R. Limits of lithography. Proceedings of IEEE, 2001, 89 (3): 366-374

7. Kneer B, Migura S, Kaiser W, et al. EUV lithography optics for sub$9 \mathrm{~nm}$ resolution. Extreme Ultraviolet (Euv) Lithography VI, 2015, $94221 \mathrm{G}$

8. Jia Y, Li Y, Liu L, et al. A method for compensating the polarization aberration of projection optics in immersion lithography. In: Proceedings of 7th International Symposium on Advanced Optical Manufacturing and Testing Technologies: Design, Manufacturing, and Testing of Micro- and Nano-Optical Devices and Systems. 2014, 928309

9. Voelkel R. Micro-optics: Enabling technology for illumination shaping in optical lithography. Optical Microlithography XXVII, 2014, $90521 \mathrm{U}$

10. Wagner C, Harned N. EUV lithography: Lithography gets extreme. Nature Photonics, 2010, 4(1): 24-26

11. Yumoto H, Mimura H, Koyama T, et al. Focusing of X-ray freeelectron laser pulses with reflective optics. Nature Photonics, 2013, 7(1): 43-47

12. Strelkov V V. High-order optical processes in intense laser field: Towards nonperturbative nonlinear optics. Physical Review A, 2016, 93(5): 053812

13. Dong B, Wang R. Laser beam cleanup using improved model-based wavefront sensorless adaptive optics. Chinese Optics Letters, 2016, 14(3): 031406-031409

14. Holly C, Traub M, Hoffmann D, et al. Monocrystalline CVDdiamond optics for high-power laser applications. High-Power Laser Materials Processing: Lasers, Beam Delivery, Diagnostics, and Applications, 2016, V, 974104

15. Clampin M. Recent progress with the JWST observatory. Space Telescopes and Instrumentation 2014: Optical, Infrared, and Millimeter Wave, 2014, 914302

16. Rao C, Zhu L, Rao X, et al. Second generation solar adaptive optics for 1-m new vacuum solar telescope at the Fuxian solar observatory. Chinese Optics Letters, 2015, 16(2): 1-3

17. Hashiguchi D H, Murder J M, Paquin R A. The evolution of beryllium space telescope optics. SAMPE Journal, 2015, 51(6): 4048

18. Lousberg G P, Moreau V, Schumacher J M, et al. Design and analysis of an active optics system for a 4-m telescope mirror combining hydraulic and pneumatic supports. Optical Systems
Design 2015: Optical Design and Engineering VI, 2015, 962624

19. Matsusaka K, Ozawa S, Yoshida R, et al. Ultracompact optical zoom lens for mobile phone. Digital Photography III, 2007, 650203

20. Shieh H P D, Huang Y P, Chien K W. Micro-optics for liquid crystal displays applications. Journal of Display Technology, 2005, 1(1): $62-76$

21. Fang Y C, Tsai H L, Chien Y H, et al. 2X optical digital zoom lens with short total length and extremely small front aperture for twomillion-pixel CMOS on mobile phones. In: Proceedings of SPIE International Optical Design Conference 2006. 2006, 6342: I3421I3421

22. Brinksmeier E, Mutlugunes $\mathrm{Y}$, Klocke F, et al. Ultra-precision grinding. CIRP Annals-Manufacturing Technology, 2010, 59(2): 652-671

23. Cheung C F, Ho L T, Charlton P, et al. Analysis of surface generation in the ultraprecision polishing of freeform surfaces. In: Proceedings of the Institution of Mechanical Engineers Part B: Journal of Engineering Manufacture. 2010, 224(1): 59-73

24. Komanduri R, Lucca D A, Tani Y. Technological advances in fine abrasive processes. CIRP Annals-Manufacturing Technology, 1997, 46(2): 545-596

25. Suzuki H, Hamada S, Okino T, et al. Ultraprecision finishing of micro-aspheric surface by ultrasonic two-axis vibration assisted polishing. CIRP Annals-Manufacturing Technology, 2010, 59(1): 347-350

26. Doetsch R N. History of Microscope. Science, 1961, 133(3456): 946-947

27. Herzberg M. History of Image of Microscope. Optik (Stuttgart), 1973, 39: 93-98

28. Cohen I B. The History of the Telescope. Henry C. King. Isis, 1957, 48(3): 357-358

29. Gonick L, Alschuler W. A brief history of the telescope. Science, 2009, 323(5912): 330-331

30. Warner D J. An acre of glass: A history and forecast of the telescope. Technology and Culture, 2007, 48(1): 231-232

31. Konig W, Koch N. Aspherical glass surfaces and options for their production. Feinwerktechnik \& Messtechnik, 1990, 98: 254-258

32. Nicholas D J, Boon J E. The generation of high precision aspherical surfaces in glass by CNC machining. Journal of Physics D: Applied Physics, 1981, 14(4): 593-600

33. Optics J D R P. Precision Glass Molding Technical Brief. Rochester Precision Optics, 2007, 1-17

34. lkawa N, Donaldson R R, Komanduri R, et al. Ultraprecision metal cutting-The past, the present and the future. CIRP Annals -Manufacturing Technology, 1991, 40(2): 587-594

35. Nakasuji T, Kodera S, Hara S, et al. Diamond turning of brittle materials for optical components. CIRP Annals-Manufacturing Technology, 1990, 39(1): 89-92

36. Fang F, Liu X, Lee L C. Micro-machining of optical glasses-A review of diamond-cutting glasses. Sadhana, 2003, 28: 945-955

37. Yi A Y, Jain A. Compression molding of aspherical glass lenses-A combined experimental and numerical analysis. Journal of the American Ceramic Society, 2005, 88(3): 579-586

38. Aono Y, Negishi M, Takano J. Development of large-aperture aspherical lens with glass molding. Advanced Optical Manufacturing and Testing Technology, 2000, (4231): 16-23 
39. Muranaka M, Noro Y, Takagi M, et al. Precise aspherical plastic lens for electronic appliances-Molding technology and applications. In: Lemstra P J, Kleintjens L A, eds. Integration of Fundamental Polymer Science and Technology. 1991, 5: 385-389

40. Liu W, Zhang L. Thermoforming mechanism of precision glass moulding. Applied Optics, 2015, 54(22): 6841-6849

41. Schaub M, Schwiegerling J, Fest E C, et al. Molded Optics Design and Manufacture. New York: CRC Press, 2011

42. Thorlabs. https://www.thorlabs.hk/navigation.cfm, 2016 (in Chinese)

43. Nelson J, Scordato M, Schwertz K, et al. Precision lens molding of asphero diffractive surfaces in chalcogenide Materials. Optifab 2015, 2015, 96331L

44. Mahajan P, Dora P T, Sandeep T S, et al. Optimized design of optical surface of the mold in precision glass molding using the deviation approach. International Journal for Computational Methods in Engineering Science and Mechanics, 2015, 16(1): 5364

45. Su L J, Chen Y, Yi A Y, et al. Refractive index variation in compression molding of precision glass optical components. Applied Optics, 2008, 47(10): 1662-1667

46. Su L J, Wang F, He P, et al. An integrated solution for mold shape modification in precision glass molding to compensate refractive index change and geometric deviation. Optics and Lasers in Engineering, 2014, 53: 98-103

47. Tseng S F, Lee C T, Huang K C, et al. Mechanical properties of Pt-Ir and Ni-Ir Binary alloys for glass-molding dies coating. Journal of Nanoscience and Nanotechnology, 2011, 11(10): 8682-8688

48. Bernhardt F. Faster mold coating tests make glass processing more efficient. Photonics Spectra, 2013, 47(8): 36-39

49. Zhao W, Chen Y, Shen L G, et al. Refractive index and dispersion variation in precision optical glass molding by computed tomography. Applied Optics, 2009, 48(19): 3588-3595

50. Fotheringham U, Baltes A, Fischer P, et al. Refractive index drop observed after precision molding of optical elements: A quantitative understanding based on the Tool-Narayanaswamy-Moynihan model. Journal of the American Ceramic Society, 2008, 91(3): 780-783

51. Sojecki A. Changes of the refractive index during the moulding process. Optical Manufacturing and Testing, 1995, 2536: 475477

52. Yan J, Oowada T, Zhou T, et al. Precision machining of microstructures on electroless-plated NiP surface for molding glass components. Journal of Materials Processing Technology, 2009, 209(10): 4802-4808

53. Hou J, Wang C, Bai Y. Research on crafts of Ni-P-SiC electroless composite plating on surface performances of the mould. Advanced Polymer Science and Engineering, 2011, 221: 389-393

54. Sawa Y, Yamashita K, Kitadani T, et al. Fabrication of high hardness Ni mold with electroless nickel-boron thin layer. Microsystem Technologies, 2010, 16(8-9): 1369-1375

55. Chon K S, Namba Y. Single-point diamond turning of electroless nickel for flat X-ray mirror. Journal of Mechanical Science and Technology, 2010, 24(8): 1603-1609

56. Yamaguchi T, Higuchi M, Shimada S, et al. Tool life monitoring during the diamond turning of electroless Ni-P. Precision Engineer- ing, 2007, 31(3): 196-201

57. Parkinson B R. Status of the nickel plating and electroforming industry. Transactions of the Metal Finishers Association of India, 1996, 5: 231-236

58. Chao C L, Chang C J, Chen C C, et al. Precision grinding of tungsten carbide mold insert for molding of sub-millimeter glass aspheric lenses. In: Proceedings of International Conference on Optics in Precision Engineering and Nanotechnology (ICOPEN2013). 2013, 87691U

59. Shin J, Tanaka S I, Esashi A. Nanostructured silicon carbide molds for glass press molding. In: Proceedings of 2007 2nd IEEE International Conference on Nano/Micro Engineered and Molecular Systems. IEEE, 2007, 1-3: 1152-1155

60. Min K O, Tanaka S, Esashi M. Micro/nano glass press molding using silicon carbide molds fabricated by silicon lost molding. In: Proceedings of 18th IEEE International Conference on Micro Electro Mechanical System. IEEE, 2005, 475-478

61. Maehara H, Murakoshi H. Quartz glass molding by precision glass molding method. Transactions of the Institute of Electrical Engineers of Japan, 2001, 122(10): 494-497

62. Liu W D, Liu M, Zhang L C. Oxidation-induced mechanical deterioration and hierarchical cracks in glassy carbon. Carbon, 2016, 100: 178-186

63. Chang Y Y, Wu C J. Mechanical properties and impact resistance of multilayered TiAlN/ZrN coatings. Surface and Coatings Technology, 2013, 231: 62-66

64. Hagen J, Burmeister F, Fromm A, et al. Iridium coatings with titanium sub-layer deposited by RF magnetron sputtering: Mechanical properties and contact behavior with RoHS-compliant glass melt. Plasma Processes and Polymers, 2009, 6(S1): S678-S683

65. Fischbach K D, Georgiadis K, Wang F, et al. Investigation of the effects of process parameters on the glass-to-mold sticking force during precision glass molding. Surface and Coatings Technology, 2010, 205(2): 312-319

66. Masuda J, Yan J, Zhou T, et al. Thermally induced atomic diffusion at the interface between release agent coating and mould substrate in a glass moulding press. Journal of Physics D: Applied Physics, 2011, 44(21): 215302-215313

67. Zhu X, Wei J, Chen L, et al. Anti-sticking Re-Ir coating for glass molding process. Thin Solid Films, 2015, 584: 305-309

68. Vetter J. 60 years of DLC coatings: Historical highlights and technical review of cathodic arc processes to synthesize various DLC types, and their evolution for industrial applications. Surface and Coatings Technology, 2014, 257: 213-240

69. Bernhardt F, Georgiadis K, Dolle L, et al. Development of a ta-C diamond-like carbon (DLC) coating by magnetron sputtering for use in precision glass molding. Materialwiss Werkst, 2013, 44(8): 661666

70. Rieser D, Spie G, Manns P. Investigations on glass-to-mold sticking in the hot forming process. Journal of Non-Crystalline Solids, 2008, 354(12): 1393-1397

71. Kleer G, Kaiser E, Döll W. Behaviour of Ti-Al-N coatings for tools applied in the thermoplastic moulding of inorganic glasses. Surface \& Coatings Technology, 1996, 79(1-3): 95-102

72. Klocke F, Georgiadis K, Dambon O, et al. A complete qualification methodology for coatings of precision glass molding tools. Optical 
Manufacturing and Testing IX, 2011, 81260T

73. Bernhardt F, Georgiadis K, Dambon O, et al. Novel testing facility for investigating wear on PGM sample tools. Optifab 2013, 2013, $88841 \mathrm{~V}$

74. Ananthasayanam B. Computional modeling of precision molding of aspheric glass optics. Dissertation for the Doctoral Degree. Clemson: Clemson University, 2008

75. Arai M, Kato Y, Kodera T. Characterization of the thermoviscoelastic property of glass and numerical simulation of the press molding of glass lens. Journal of Thermal Stresses, 2009, 32(12): 1235-1255

76. Jain A, Yi A Y. Numerical modeling of viscoelastic stress relaxation during glass lens forming process. Journal of the American Ceramic Society, 2005, 88(3): 530-535

77. Ananthasayanam B, Joseph P F, Joshi D, et al. Final shape of precision molded optics: Part I-Computational approach, material definitions and the effect of lens shape. Journal of Thermal Stresses, 2012, 35(6): 550-578

78. Ananthasayanam B, Joseph P F, Joshi D, et al. Final shape of precision molded optics: Part II-Validation and sensitivity to material properties and process parameters. Journal of Thermal Stresses, 2012, 35(7): 614-636

79. Tsai Y C, Hung C H, Hung J C. Glass material model for the forming stage of the glass molding process. Journal of Materials Processing Technology, 2008, 201(1-3): 751-754

80. Sellier M, Hann C E, Siedow N. Identification of relaxation functions in glass by mean of a simple experiment. Journal of the American Ceramic Society, 2007, 90(9): 2980-2983

81. Richter F. Upsetting and viscoelasticity of vitreous $\mathrm{SiO} 2$ : Experiments, interpretation and simulation. Dissertation for the Doctoral Degree. Berlin: Technical of University of Berlin, 2006

82. Liu W D, Ruan H H, Zhang L C. Revealing structural relaxation of optical glass through the temperature dependence of Young's modulus. Journal of the American Ceramic Society, 2014, 97(11): 3475-3482

83. Dyre J C, Olsen N B, Christensen T. Local elastic expansion model for viscous-flow activation energies of glass-forming molecular liquids. Physical Review B: Condensed Matter and Materials Physics, 1996, 53(5): 2171-2174
84. Yi A Y, Tao B, Klocke F, et al. Residual stresses in glass after molding and its influence on optical properties. Procedia Engineering, 2011, 19: 402-406

85. To Q D, He Q C, Cossavella M, et al. The tempering of glass and the failure of tempered glass plates with pin-loaded joints: Modelling and simulation. Materials \& Design, 2008, 29(5): 943-951

86. Chen Y, Yi A Y, Su L, et al. Numerical simulation and experimental study of residual stresses in compression molding of precision glass optical components. Journal of Manufacturing of Science and Engineering, 2008, 130(5): 051012

87. Ritland H N. Relation between refractive index and density of a glass at constant temperature. Journal of the American Ceramic Society, 1955, 38(2): 86-88

88. Tao B, Shen L G, Yi A, et al. Reducing refractive index variations in compression molded lenses by annealing. Optics and Photonics Journal, 2013, 3(02): 118-121

89. Zhu Y, Wang Y, Na J, et al. A framework of cloud supported collaborative design in glass lens moulds based on aspheric measurement. Current Developments in Lens Design and Optical Engineering XIV, 2013, 88411A

90. Wu T C, Tsai Y C, Hung C H. Die shape optimization on molding process of optical glass lens. Taoyuan, 2007

91. Sellier M. Optimal process design in high-precision glass forming. International Journal of Forming Processes, 2006, 9(1): 61-78

92. Sellier M, Breitbach C, Loch $\mathrm{H}$, et al. An iterative algorithm for optimal mould design in high-precision compression moulding. In: Proceedings of the International of Mechanical Engineering Part B: Journal of Engineering Manufacture. 2007, 221(1): 25-33

93. Mahajan P, Dora P T, Sandeep T S, et al. Optimized design of optical surface of the mold in precision glass molding using the deviation approach. International Journal for Computational Methods in Engineering Science and Mechanics, 2015, 16(1): 5364

94. Sellier M. Optimization in high-precision glass forming. In: Bucchianico A D, Mattheij R M M, Peletier M A, eds. Progress in Industrial Mathematics at ECMI 2004. Berlin: Springer, 2006, 8: 381-385

95. Kreilkamp H, Staasmeyer J H, Niendorf L. The future of glass optics replication. Optik \& Photonik, 2016, 11(3): 28-31 